\begin{abstract}
The abstract for your chapter is reproduced below for your reference. Please note that this will not appear in the final printed version of your chapter.
\end{abstract}

Hybrid bio-based aerogels exhibit enhanced synergistic properties as compared to their corresponding constituents. The technology has attracted increasing research interests, particularly as these syntheses lead to formation of various microstructures with different properties of the composite. In this chapter, the recent developments in hybrid bio-based aerogels are introduced, including the use of new precursors, doping techniques, and microstructure, as well as morphology of composites. Applications of the new precursors such as collagen, xyloglucan, pectin, lignin, aniline, polypyrrole, graphene oxide and halloysite nanotubes are discussed separately. Detailed syntheses of hybrid bio-based aerogels are elaborated in the stages of sol formation, gelation, doping and drying. Micrographic images are categorized based on the microstructures of the hybrid aerogels, where the formation of each type of microstructure is illustrated and discussed. At the end of the chapter, a new technique, called synchrotron X-ray tomography is introduced, which is able to probe the degree of anisotropy of the hybrid aerogels. 
CHAPTER 7

\section{Hybrid Green Aerogels: Processing and Morphology}

KOW KIEN-WOH*a AND ROZITA YUSOFF ${ }^{\mathrm{b}}$

${ }^{a}$ Department of Chemical and Environmental Engineering, Faculty of Science and Engineering, The University of Nottingham Ningbo China, Ningbo 315100, China; ${ }^{b}$ Department of Chemical Engineering, Faculty of Engineering, University of Malaya, 50603 Kuala Lumpur, Malaysia

*Email: Kien-Woh.Kow@nottingham.edu.cn; kowkw@outlook.com

\subsection{Types of Hybrid Bio-based Aerogels}

Hybrid bio-based aerogels are formed by incorporating other phases of materials into bio-based aerogels. The rationale for such hybridization can be one of the following, or a combination of both:

(i) Synergistic effect

Pure aerogels usually exhibit undesirable properties that might weaken their performance. Incorporating other materials can have a remarkable positive impact on the properties of the hybrid aerogels, resulting in better stability (reduced agglomeration of particles, oxidation rate), mechanical properties (reduced fragility ${ }^{1-11}$ ), adsorption performance (adsorption capacity, ${ }^{12-16}$ selectivity ${ }^{17-21}$ ), thermal properties, ${ }^{3-7,9,22-29}$ electrical properties, ${ }^{2,30}$ magnetism $^{31-34}$ and biocompatibility (scaffold for tissue engineering, ${ }^{35-38}$ drug delivery ${ }^{39-42}$ ).

(ii) Reaction template

The porous structure of aerogels is suitable to act as a template for the synthesis of nanoparticles. This template can nucleate and control

Green Chemistry Series No. 58

Biobased Aerogels: Polysaccharide and Protein-based Materials Edited by Sabu Thomas, Laly A. Pothan and Rubie Mavelil-Sam

(C) The Royal Society of Chemistry 2018

Published by the Royal Society of Chemistry, www.rsc.org 
the growth of nanoparticles in three ways. The simplest way is by acting as an inert support to control the uniform size and/or shape growth. ${ }^{24,31,43-45}$ In addition, particle size, shape and pore restriction can also immobilize particles from agglomeration. Such immobilization is crucial to fully utilize the functionality of nanoparticles, which otherwise may be severely deteriorated upon agglomeration. However, this physical immobilization may still be dislodged from the template when it is used under vigorous agitation. The second way for the template to hold the nanoparticles in place is by electrostatic interaction and hydrogen bonding originating from the hydroxyl and oxygen-rich groups. ${ }^{33,46}$ These functional groups can serve as nano-reacting sites, whereby inorganic nanoparticles can be anchored tightly to avoid particle agglomeration and hence achieve controlled growth. Finally, such functional groups can also act as reducing sites that react with nanoparticle precursors to nucleate nanoparticles. ${ }^{10,34,47-57}$ The resulting hybrid bio-based aerogel may $^{24,31,33,34,43-45,48-50}$ or may not ${ }^{46}$ exhibit a synergistic effect. In some cases, cellulose aerogel was calcined ${ }^{58}$ to recover the nanoparticles, as cellulose can easily be burned.

In the early 2000s, hybrid aerogels were first reported separately by two research teams led by Hunt ${ }^{41}$ and Risen ${ }^{59}$ respectively. Hunt's team tried to improve the biocompatibility of a silica aerogel by adding chitosan, whereas Risen's team focused on using a chitosan-silica aerogel as a template to synthesize metallic nanoparticles. Figure 7.1 shows that during the period from 2000 to 2005, this area was mainly dominated by Risen's research team, while research on bio-based hybrid aerogels was mainly silent during this period. Bio-based hybrid aerogels regained attention amongst the research community a few years after the success of a cellulose aerogel, which was synthesized by Josef's research group in $2006 .{ }^{60}$ This cellulose aerogel offered a new bio-based precursor to synthesize hybrid aerogels. The high biocompatibility of cellulose aerogels that could potentially be applied to tissue engineering and drug delivery caused research on cellulosic hybrid aerogels to boom after 2011.

It is generally accepted that bio-based hybrid aerogels contain two or more phases with various chemical components. However, there is no classification for the type of structures formed. Hence, it is crucial to define some of the common terms that describe different types of hybrid structures. The essence of an aerogel structure is the continuous backbone that gives rise to its rigidity and porosity. Throughout this chapter, the term "skeletal phase" is used to describe this continuous backbone of the aerogel. This term is equivalent to "primary phase", "primary network", "host" and "backbone" in the literature. Many terms have been used to describe other phase/s that were added to synthesize the hybrid aerogel. All these terms are related to how these phases are being incorporated into the skeletal phase, which includes the secondary phase, incorporated phase, embedded phase, 


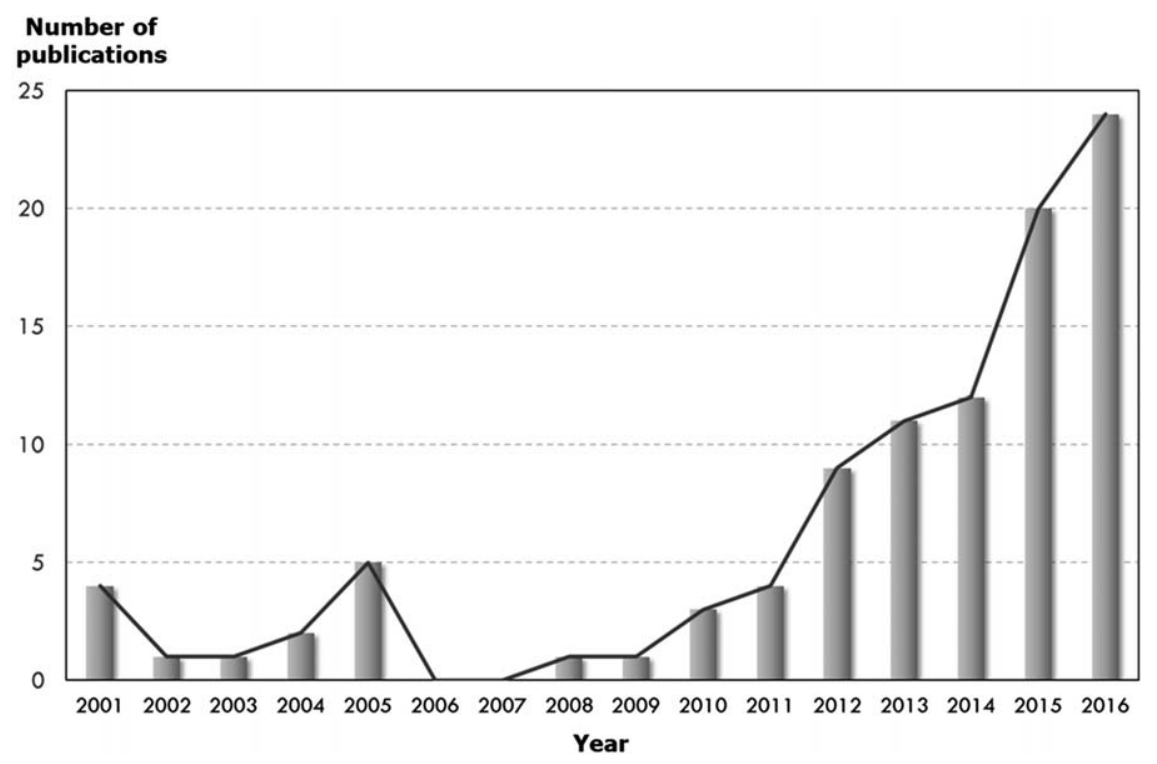

Figure 7.1 Number of publications related to bio-based hybrid aerogels from 2000-2016 (based on the bibliography list in this chapter).

anchored phase, coated phase, dopant, shell structure, encapsulation agent, filling agent and the cross-linked agent. Hence, in general, the term "incorporated phase" is used to describe any material added to the skeletal phase in the hybrid aerogel throughout this chapter. The incorporated phase can be further divided into the following categories, depending on the hybrid structure formed:

(a) Coating agent

The incorporated phase forming a monolayer or multilayer particles on the surface of the skeletal phase throughout the gel network as shown in Figure 7.2b.

(b) Encapsulation

Similar to the coating agent, the incorporated phase forms a monolayer or multilayer particles on the surface of the skeletal phase. However, the encapsulation only involves the outer surface of the skeletal phase. It is the outer surface of the skeletal phase that is either encapsulating (shell) other particles (please see Figure 7.2d) or being encapsulated (core) by other particles (see Figure 7.2c). In either case, the inner pores of the skeletal phase are not in contact with other particles. Hence, it is less homogenous as compared with the coating agent.

(c) Anchored phase

The incorporated phase is grafted onto the skeletal phase as shown in Figure 7.2e. One end of the anchored phase is usually bonded to the active sites of the skeletal phase, which is spaced spatially in the 


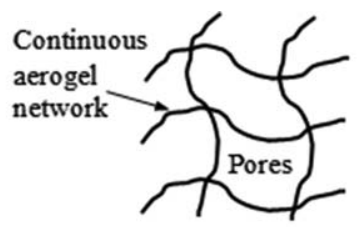

(a)

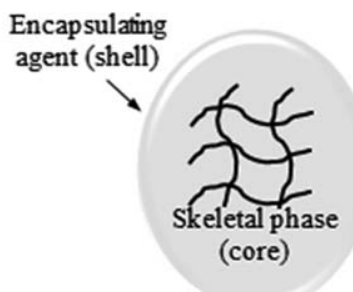

(c)

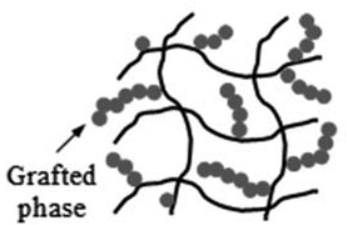

(e)

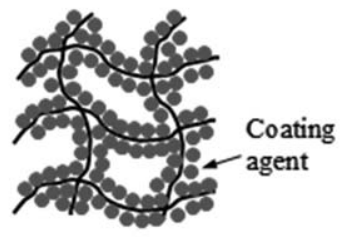

(b)

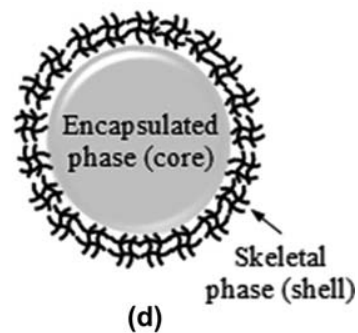

15

20

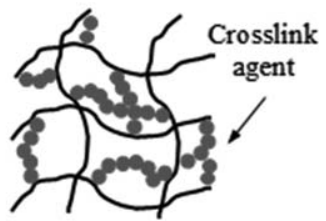

(f)

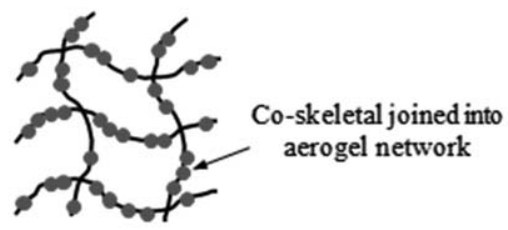

(g)

Figure 7.2 Structures in the hybrid aerogel: (a) skeletal phase; (b) coating; (c) encapsulation (skeletal phase as core); (d) encapsulation (skeletal phase as shell); (e) anchor phase; (f) crosslink agent and (g) co-skeletal phase.

network of the skeletal phase, whereas the other end of the incorporated phase is "free" and not bonded to the skeletal phase.

(d) Crosslink agent

Unlike the anchored phase, the crosslink agent binds the ends of its particles to at least two sides of the skeletal phase (see Figure 7.2f). 
Hence, two or more sides of the skeletal phase are linked together by the crosslink agent.

(e) Co-skeletal phase

The incorporated phase is joined into the skeletal phase to form part of the network as shown in Figure 7.2g. Since both phases form the network, the phase having a smaller composition is termed the "co-skeletal" phase.

\subsubsection{Organo-hybrid}

The organic compounds that are incorporated into bio-based aerogels are mostly aimed toward drugs delivery purposes, as shown in Table 7.1. Less emphasis has been placed on improving the mechanical or thermal properties, as in the case of inorgano-hybrid aerogels. This may be due to the nature of the organic compound, commonly having weak bonding and thus not showing

Table 7.1 Types of organo-hybrid bio-based aerogel.

\begin{tabular}{|c|c|c|}
\hline Bio-based aerogel & Incorporated phase & Purpose \\
\hline Protein & $\begin{aligned} \text { (i) } & \text { Alginate } \\
\text { (ii) } & \text { Ketoprofen } \\
\text { (iii) } & \text { Ibuprofen } \\
\text { (iv) } & \text { Nano-crystalline } \\
& \text { cellulose }\end{aligned}$ & $\begin{array}{l}\text { Reduce brittleness }{ }^{1} \\
\text { Drug delivery }{ }^{39} \\
\text { Drug delivery }{ }^{40} \\
\text { Nutraceuticals }^{61}\end{array}$ \\
\hline $\begin{array}{l}\text { Nano-crystalline } \\
\text { cellulose }(\text { NCC) }\end{array}$ & (i) Bleached cellulose fibers & Mechanical properties ${ }^{5}$ \\
\hline $\begin{array}{l}\text { Nano-fibrillated } \\
\text { cellulose (NFC) }\end{array}$ & $\begin{array}{l}\text { (i) Polyvinyl-alcohols } \\
\text { (ii) Xyloglucan } \\
\text { (iii) Bleached cellulose fibers } \\
\text { (iv) Methyl trichlorosilane } \\
\text { (v) Collagen } \\
\text { (vi) Poly( } N \text {-isopropyl- } \\
\\
\text { acrylamide) } \\
\text { (vii) Various polymers }\end{array}$ & $\begin{array}{l}\text { Superabsorbent } \\
\text { Mechanical properties } \\
\text { Mechanical properties }^{5} \\
\text { Oil absorption } \\
\text { Biocompatibility }^{64} \\
\text { Thermo-responsiveness }^{65} \\
\text { Biocompatibility }^{66}\end{array}$ \\
\hline Chitosan & $\begin{array}{l}\text { (i) Gelatin } \\
\text { (ii) Polybenzoxazine }\end{array}$ & $\begin{array}{l}\text { Mechanical properties } \\
\mathrm{CO}_{2} \text { adsorption }\end{array}$ \\
\hline Alginate & $\begin{array}{l}\text { (i) Pectin and carrageenan } \\
\text { (ii) Starch } \\
\text { (iii) Gelatin } \\
\text { (iv) Lignin }\end{array}$ & $\begin{array}{l}\text { Drug delivery, }{ }^{42} \text { porous } \\
\text { structure } \\
\text { Mechanical properties, }^{13} \\
\text { porous structure }^{68} \\
\text { Mechanical properties, } \\
\text { porous structure }^{68} \\
\text { Non-cytotoxicity, }^{38} \text { porous } \\
\text { structure }^{68}\end{array}$ \\
\hline Agar & $\begin{array}{l}\text { (i) Cellulose/rice starch/zein } \\
\text { protein }\end{array}$ & $\begin{array}{l}\text { Dissolution and crosslink } \\
\text { agent }^{69}\end{array}$ \\
\hline Pectin & (i) Aniline & Conductive polymer ${ }^{70}$ \\
\hline
\end{tabular}


much of the synergistic effect in terms of mechanical and thermal properties. On the other hand, organo-hybrid bio-based aerogels that are totally made up of organic compounds may have the advantage of being biocompatible and biodegradable. In this sense, organo-hybrid aerogels are considered to be more environmental friendly as compared to the inorgano-hybrid aerogels.

\subsubsection{Inorgano-hybrid}

Incorporating inorganic compounds into bio-based aerogels is usually targeted towards improving the physical properties such as mechanical, thermal, magnetic and adsorption properties. The inorganic incorporated compounds consist mainly of two categories of materials, these are nanomaterials and ceramics. While ceramics are incorporated to improve the thermal and adsorption properties of aerogels, nanomaterials are used to add on a wide range of functionalities such as antibacterial activity, photocatalytic activity, photo-luminescence, magnetic properties, mechanoresponsiveness and so forth, as stated in Table 7.2.

\subsection{Synthesis}

Many routes were proposed to synthesize hybrid bio-based aerogels. In general the synthesis involves the following steps: (i) formation of sol from raw materials, (ii) gelation of sol to form the skeletal phase, (iii) doping incorporated phase to the skeletal phase, and (iv) drying of the hybrid gel.

\subsubsection{Formation of Sol}

Raw materials are dissolved to form the sol which contains small clusters (monomers, dimers, oligomers) of atoms prior to gelation. The dissolution methods of hybrid bio-based aerogels are mainly adapted from the pure biobased aerogels such as cellulose, chitosan, pectin, alginate, and so forth. Among the bio-based precursors, those with limited solubility in water pose a major challenge in the dissolution step. The insolubility of precursors such as cellulose and chitin is attributed to the tight hydrogen bonding between the polymer chains. Hence, both chemical and physical pre-treatments are required to weaken the hydrogen bonding prior to dissolution. Hydrogen bonding cleavage can be accomplished using either one of the following treatments:

(a) Polar solvent systems such as N-methylmorpholine oxide (NMMO). ${ }^{22,60,90}$

(b) TEMPO (2,2,6,6-tetramethylpiperidine-1-oxylradical) mediated oxidation and related hybrid solvents. ${ }^{5,20,74,91}$

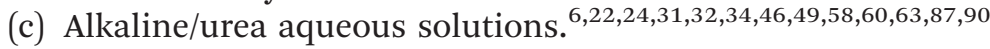

(d) Ionic liquids (IL). ${ }^{22,44,90,92}$

(e) Deep eutectic solvents (DES). ${ }^{90}$

These chemical pre-treatments are usually accompanied by other physical pre-treatments such as freezing-thawing, mechanical shearing and/or ultrasonic impingement to further weaken the hydrogen bonding. 
AQ:1 Table 7.2 Types of inorgano-hybrid bio-based aerogel.

\begin{tabular}{|c|c|c|}
\hline Bio-based aerogel & Incorporated phase & Purpose \\
\hline $\begin{array}{l}\text { Nano-crystalline } \\
\text { cellulose }(\text { NCC) }\end{array}$ & (i) Graphene oxide & Adsorption $^{18}$ \\
\hline \multirow{12}{*}{$\begin{array}{l}\text { Nano-fibrillated } \\
\text { cellulose (NFC) }\end{array}$} & (i) Silver & Mechanical properties ${ }^{71}$ \\
\hline & (ii) Silica & $\begin{array}{l}\text { Thermal stability }{ }^{72} \text { mechanical } \\
\text { properties, }{ }^{6,73} \text { heat } \\
\text { insulation, }{ }^{6,9,23} \text { acoustic } \\
\text { insulation }{ }^{23}\end{array}$ \\
\hline & (iii) Zeolite & Heat insulation $^{74}$ \\
\hline & (iv) Aluminum hydroxide & Flame retardancy $^{28}$ \\
\hline & (v) Zinc oxide & Antibacterial activity $^{46}$ \\
\hline & (vi) Polypyrrole and silver & $\begin{array}{l}\text { Antibacterial activity, }{ }^{49} \text { electrical } \\
\text { conductive and pressure } \\
\text { responsive properties }\end{array}$ \\
\hline & (vii) Titanium oxide & $\begin{array}{l}\text { Adsorption, }{ }^{76,77} \text { mechanical } \\
\text { properties, }{ }^{78} \text { photocatalytic } \\
\text { activity }{ }^{58,79,80}\end{array}$ \\
\hline & (viii) Carbon nanotube & $\begin{array}{l}\text { Mechanoresponsive } \\
\text { conductivity, }{ }^{33,34} \text { electrical } \\
\text { fatigue behaviour }\end{array}$ \\
\hline & (ix) Cobalt ferrites & $\begin{array}{l}\text { Magnetic behaviour, }{ }^{31,33} \\
\text { mechanical properties }^{82}\end{array}$ \\
\hline & (x) Graphene oxide & $\begin{array}{l}\text { Electromagnetic shielding, } \\
\text { heat insulation }\end{array}$ \\
\hline & $\begin{array}{l}\text { (xi) Silver, gold, and } \\
\text { platinum } \\
\text { nanoparticles }\end{array}$ & Supporting medium ${ }^{4,45}$ \\
\hline & (xii) $\mathrm{Ag}-\mathrm{Ag}_{2} \mathrm{~S}$ & Catalysis $^{47}$ \\
\hline \multirow[t]{11}{*}{ Chitosan } & (i) Graphene oxide & $\mathrm{CO}_{2}$ capture ${ }^{12}$ \\
\hline & (ii) Graphene & Capacitance $^{30}$ \\
\hline & (iii) Silica & $\begin{array}{l}\text { Porous structure, }{ }^{11,59} \text { mechanica } \\
\text { properties, }{ }^{8} \text { composite } \\
\text { structure, }{ }^{83} \text { biocompatibility, }{ }^{41} \\
\text { absorption, }{ }^{84} \\
\text { adsorption }{ }^{24,46,49,85}\end{array}$ \\
\hline & (iv) Zeolite & Adsorption $^{16}$ \\
\hline & (v) Titanium oxide & Surface $_{\text {area }}{ }^{11}$ \\
\hline & (vi) Silica-Au(III) & $\begin{array}{l}\text { Photo-formation of gold } \\
\text { nanoparticles }\end{array}$ \\
\hline & (vii) Montmorillonite & Adsorption $^{14}$ \\
\hline & (viii) Magnesium hydroxide & Flame retardancy ${ }^{24}$ \\
\hline & $\begin{array}{l}\text { (ix) } \mathrm{Zn}-\mathrm{In}-\mathrm{Cu} \text { alloy } \\
\text { quantum dot }\end{array}$ & Photo-luminiscence $^{44}$ \\
\hline & (x) Aniline-silica & $\begin{array}{l}\text { Template to synthesize silver anc } \\
\text { gold nanoparticles }{ }^{48}\end{array}$ \\
\hline & $\begin{array}{l}\text { (xi) Metallic nanoparticles- } \\
\text { silica }\end{array}$ & Functionalized composite ${ }^{86}$ \\
\hline Chitin & (i) Halloysite nanotubes & Adsorption $^{87}$ \\
\hline Pectin & (i) Silica & Heat insulation $^{29}$ \\
\hline \multirow[t]{3}{*}{ Alginate } & (i) Halloysite nanotubes & Cytocompatibility $^{37}$ \\
\hline & (ii) Silica & Porosity $^{88}$ \\
\hline & $\begin{array}{l}\text { (iii) Carbon nanotubes/ } \\
\text { silver }\end{array}$ & Pressure sensing ${ }^{89}$ \\
\hline Xanthan gum & (i) Sodium montmorillonite & Flame retardancy ${ }^{26}$ \\
\hline Gum Arabic & (i) Sodium montmorillonite & Heat insulation ${ }^{7}$ \\
\hline
\end{tabular}

(i) Sodium montmorillonite 
In addition to the bio-based components, there are hybrid gels with other precursors (such as silica) that need to be prepared as a sol. Two or more-sol systems can either be gelled separately to be used later or gelled directly together (co-gelation) to form the hybrid.

\subsubsection{Gelation}

Gelation of the dissolved precursor/s occurs when these atomic clusters are condensed and polymerized. The process is heavily dependent on the electric potential of these atomic clusters, which in turn reflect on the $\mathrm{pH}$ of the sol. With appropriate $\mathrm{pH}$ adjustment, which is usually done by addition of acids and bases to the sol, rapid gelation can occur when the iso-electric point is achieved among these clusters. An alternative to the network formation is to crosslink these atomic clusters with a crosslinking agent. This method is especially crucial when the sol concentration is too low to form a rigid network.

Interestingly, besides $\mathrm{pH}$ adjustment and crosslinking, some have reported accelerated gelation by (i) pressurized carbon dioxide and (ii) addition of graphene oxide sheet (GOS). In the pressurized $\mathrm{CO}_{2}$ method, gelation is induced by the weak acidity of $\mathrm{CO}_{2}$ in the water containing samples of alginate, cellulose and chitosan hybrid aerogels. ${ }^{38,68,93}$ As for graphene oxide sheet, the accelerated gelation in the cellulose hybrid aerogel was confirmed by Zhang et $a l .{ }^{94}$ and it is attributed to the interaction of GOS with the cellulose chain as shown in Figure 7.3.

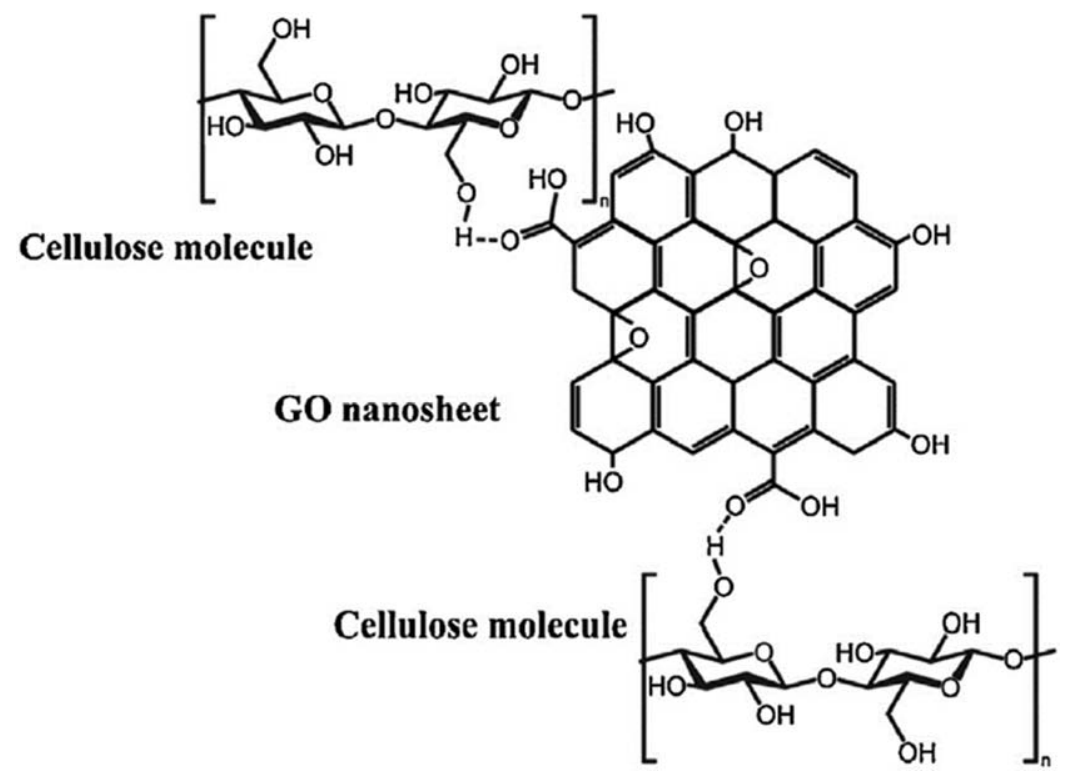

Figure 7.3 Interaction of hydrogen bonds between cellulose and GOS. ${ }^{32}$

Reprinted with permission from Carbohydrate Polymers, 150, C. Wan and J. Li, Graphene oxide/cellulose aerogels nanocomposite: Preparation, pyrolysis, and application for electromagnetic interference shielding, 172-179, Copyright 2016, with permission from Elsevier. 


\subsubsection{Doping}

The addition of an incorporated phase can either be performed (i) after the gelation of the skeletal phase or (ii) before the gelation in a co-gelation manner. In the former method, the incorporated phase is attached to the precast skeletal phase by:

(a) Deposition/encapsulation: The incorporated phase is readily deposited onto the surface of the precast skeletal phase in the form of coating $^{5,7,13,23,26,37,62,81}$ or encapsulation ${ }^{37}$ as shown in Figure 7.2. There are also incorporated phases that can only be formed after its precursor is reacted in the presence of the skeletal phase. Such a reaction may be initiated by adding other reagents, ${ }^{6,24,31,33,34,36,44,46,48,58,83,95,96}$ or be photo-catalytic $^{55}$ and so forth. For encapsulation, the incorporated phase is pre-mixed with the precursor of the skeletal phase. By adding chemical reagents, the skeletal phase evolves and encapsulates the incorporated phase within itself. ${ }^{1,1}$

(b) Silylation: This is mainly for hybrid gels containing silica where the alkyl-silanes are coated or grafted onto the skeletal phase $e^{5,63}$ as illustrated in Figure 7.2.

(c) Chemical vapor deposition (CVD): This is a thin layer of coating in nanometres, such as titania ${ }^{76,77}$ that can be functionalized. However, CVD usually requires high energy consumption and toxic materials.

(d) Active groups reduction: These are the reactive functional groups on the skeletal phase which react with the incorporated phase containing metal oxides and cause it to be reduced it to metal nanoparticles $^{31,45-47,71,86}$ which can then be attached to the skeletal phase.

(e) Crosslinked agent: This is the incorporated phase, which is commonly another polymeric species reacted with the skeletal network on its ends to join these networks together. ${ }^{37,38,68,87,98}$

Besides the above mentioned conventional methods, the co-gelation method recently received considerable attention within the research community. By having two or more miscible sol systems, co-gelation can be carried out and the incorporated phase is likely to form simultaneously with the skeletal phase. In some cases, the incorporated phase can also act as a co-skeletal phase as shown in Figure 7.2. This so called "one-pot" synthesis was carried out by mixing the precursors of the skeletal phase and the incorporated phase to form a homogenous solution, as shown in Figure 7.4.

Gelation of a mixture may be self-initiated or it can be initiated by $\mathrm{pH}$ adjustment. The following advantages can be associated with this cogelation method:

(i) Solvent reduction: In the conventional methods, the pores of the precast skeletal phase is filled with another solvent before adding 
(a)

Mixing of the

silica sol A with pectin $B$ (b)

Dissolving

the pectin

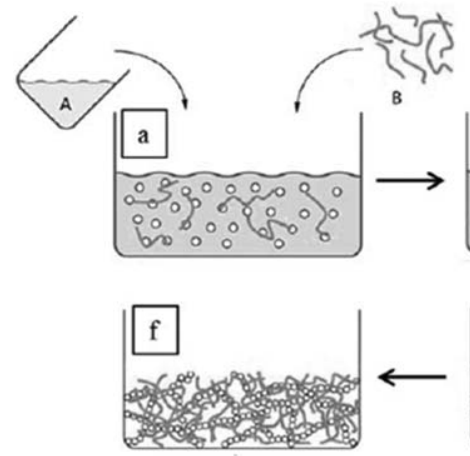

(d)

Aging the gel to promote the formation of silica network
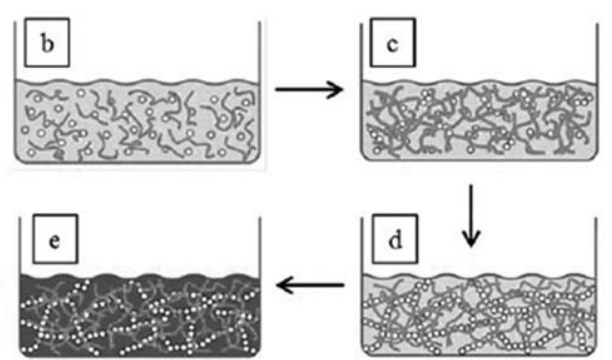

(e)

Exchange water with ethanol and hydrophobisation (c)

Making the pectin network first at low $\mathrm{pH}$

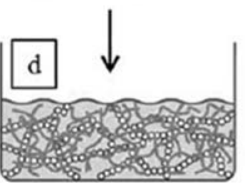

(f)

Drying with supercritical carbon dioxide

Figure 7.4 Schematic diagram of the "one-pot" synthesis of a pectin-silica hybrid aerogel. $^{29}$

Adapted from ref. 29 with permission from John Wiley and Sons, Copyright (C) 2015 Wiley-VCH Verlag GmbH \& Co. KGaA, Weinheim.

the incorporated phase. The equilibrium for mass transfer of the incorporated phase into these porous networks is easily reached due to the dilute action of the pore fluid. Thus, the extra amount of the incorporated phase is required to generate a sufficient concentration gradient for the incorporated phase to diffuse into the pores. Whereas in the co-gelation method, the incorporated phase is embedded in the pores during the formation of the skeletal phase. Hence, less of the incorporated phase is needed. ${ }^{99}$

(ii) Time saving: In the conventional method, the mass transfer of the incorporated phase into the pores of the skeletal phase is diffusion limited. This process is very time consuming and in addition a large amount of the incorporated phase is required. The duration for such a process can be largely reduced by embedding the incorporated phase prior to co-gelation. ${ }^{22,73,99}$

(iii) Alteration of the microstructure: The presence of the incorporated phase can cause an ionic or steric effect during co-gelation. As a result, evolution of the microstructure may be altered by these effects..$^{8,22,29,41,73}$ In addition, there is a possibility for the incorporated phase to join into the skeletal phase and form a co-skeletal phase $^{69}$ as illustrated in Figure 7.2. 


\subsubsection{Drying}

As in a conventional aerogel, the drying of a hybrid aerogel can be accomplished via freeze drying, supercritical drying and ambient pressure drying. A discussion of each is provided below:

(a) Supercritical drying: This is by far the best technique to preserve the pore structures of the gel. The aerogel yield contains an isotropic hierarchical structure of micro-, meso- and macropores. The products formed also suffer a lower degree of shrinkage as compared to those formed by freeze drying and ambient pressure drying.

(b) Freeze drying: This technique is well known for its ease of operation and low cost. However, the expansion of the pore fluid upon freezing can induce micro-cracks in the sample. In addition, hierarchical structures can be eliminated in the process leaving mainly macropores. Another interesting aspect of freezing is the fact that it tends to exhibit anisotropic morphology. Such a phenomenon is usually attributed to the anisotropic growth of ice crystals during freezing. ${ }^{7,27,62}$

(c) Ambient pressure drying: This is done by attaching other agents onto the surface of the gel pores, which can strengthen the skeletal phase and also reduce the surface tension of the pore fluid. The method has a great potential to be scaled up for mass production due to the simplicity and low energy consumption. However, the hybrid aerogels formed usually suffer from a large degree of shrinkage.

\subsection{Morphology}

The morphology of hybrid aerogels are usually visualized using conventional imaging techniques such as scanning electron microscopy (SEM) or field emission scanning electron microscopy (FESEM). However, transmission electron microscope (TEM) is used to confirm the presence of a crystallite, typically from metallic nanoparticles that are doped into the skeletal phase. Under certain configurations, elemental mapping can also be carried out on both the SEM and TEM images. In this section, various nanostructures of bio-based hybrid aerogels captured by SEM and TEM will be discussed. In addition, a new synchrotron X-ray tomography will be introduced. This technique is able to probe the degree of anisotropy of the incorporated phase within the skeletal phase.

\subsubsection{SEM Images}

Most of the neat bio-based aerogels usually display a 3D open structure as shown in Figure 7.5. Nevertheless, the hybrid version normally exhibits a 2D porous sheet-like nanopaper structure (Figure 7.6).

The formation of a $2 \mathrm{D}$ porous sheet may be attributed to the growth of doped materials on the skeletal phase with a 3D open structure; especially 


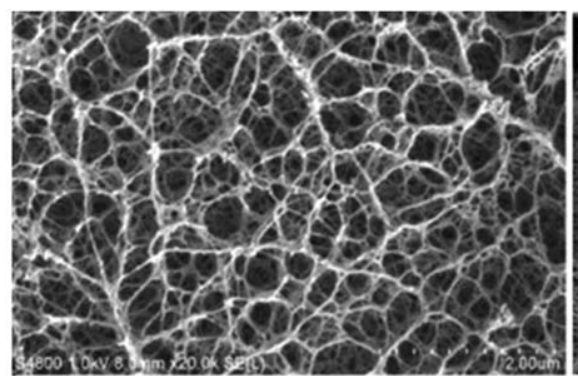

(a)

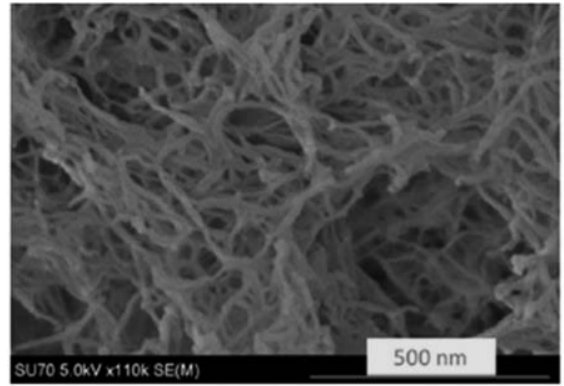

(c)

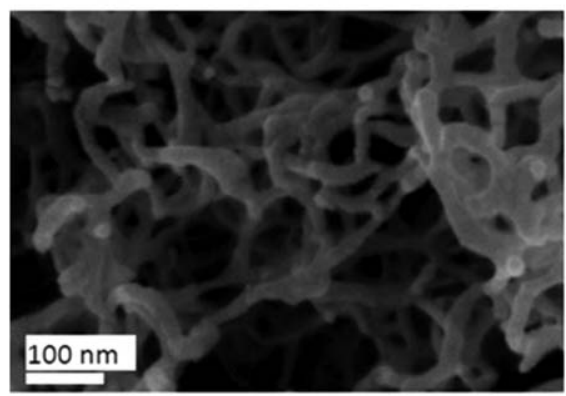

(e)

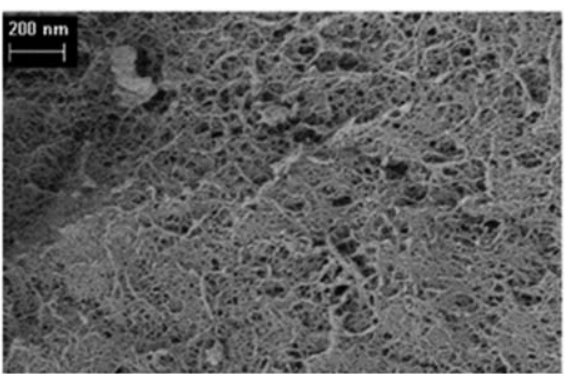

(b)

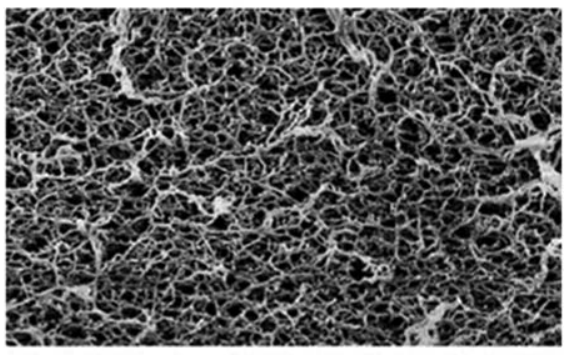

Mag: $20000 \mathrm{X}$

(d)

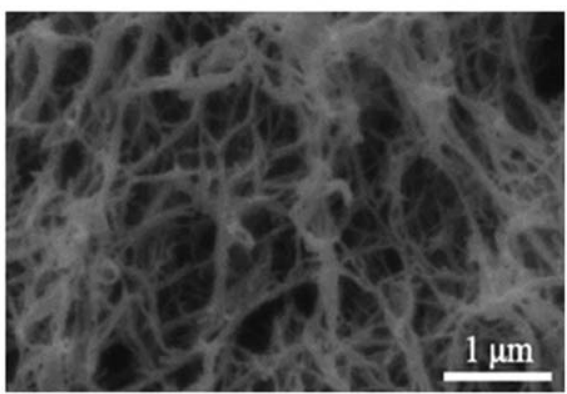

(f)

Figure 7.5 SEM images of neat (a) cellulose aerogel, ${ }^{34}$ (b) alginate aerogel, ${ }^{13}$ (c) silk fibroin, ${ }^{40}$ (d) chitosan, ${ }^{100}$ (e) pectin, ${ }^{22}$ and (f) chitin. ${ }^{101}$ Part A reprinted from Carbohydrate Polymers, 89, S. Liu, Q. Yan, D. Tao, T.Yu and X. Liu, Highly flexible magnetic composite aerogels prepared by using cellulose nanofibril networks as templates, 551-557, Copyright 2012, with permission from Elsevier. Part B reprinted from Powder Technology, 285, S. Antonyuk, S. Heinrich, P. Gurikov, S. Raman and I. Smirnova, Influence of coating and wetting on the mechanical behaviour of highly porous cylindrical aerogel particles, 34-43, Copyright 2015, with permission from Elsevier. Part C reprinted from The Journal of Supercritical Fluids, 91, M. A. Marin, R. R. Mallepally and M. A. McHugh, Silk fibroin aerogels for drug delivery applications, 84-89, Copyright 2014, with permission from Elsevier. Part D reprinted from The Journal of Supercritical Fluids, 103, L. Baldino, S. Concilio, S. Cardea, I. De Marco, E. Reverchon, Complete glutaraldehyde elimination during chitosan hydrogel drying by SC-CO2 processing, 70-76, Copyright 2015, with permission from Elsevier. Part F reproduced from ref. 101 with permission from John Wiley and Sons, (C) 2013 Wiley-VCH Verlag GmbH \& Co. KGaA, Weinheim. 


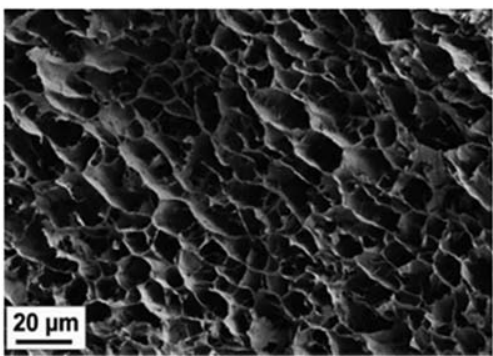

(a)

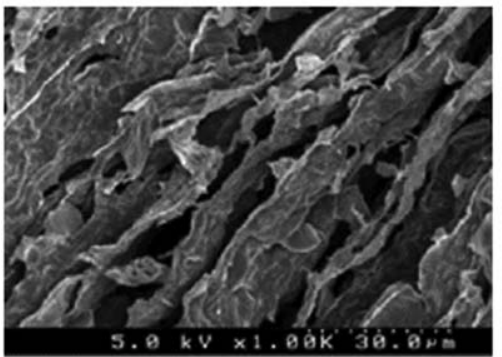

(c)

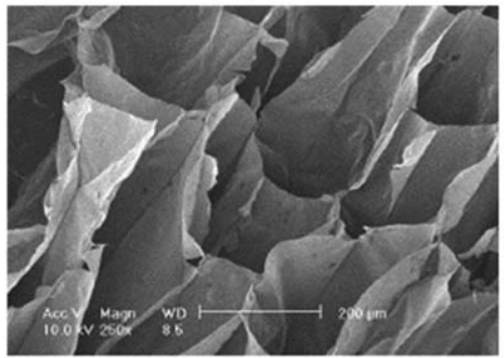

(e)

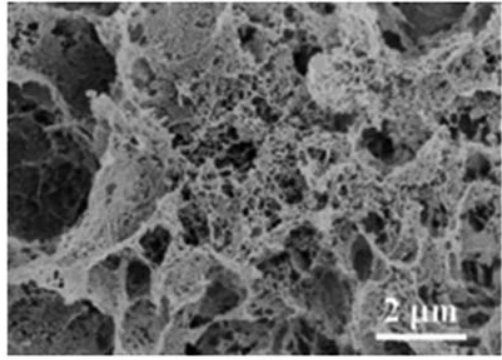

(b)

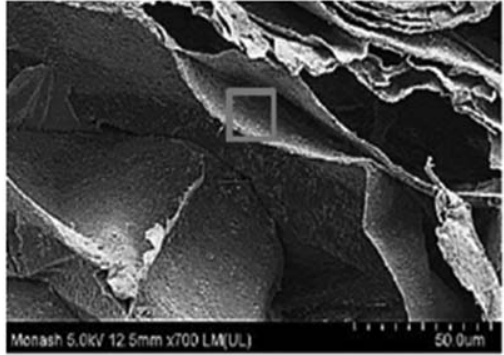

(d)

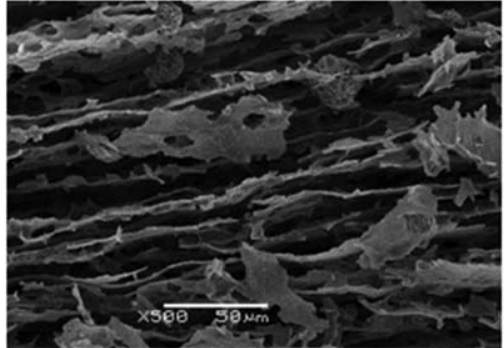

(f)

Figure 7.6 SEM images of hybrid (a) cellulose-functionalized carbon nanotubes aerogel ${ }^{81}$ (b) cellulose-graphene oxide aerogel, ${ }^{32}$ (c) chitosan-graphene oxide aerogels, ${ }^{12}$ (d) alginate-halloysite aerogel, ${ }^{102}$ (e) chitin-halloysite nanotubes aerogel, ${ }^{87}$ and (f) gum Arabic-clay aerogel. ${ }^{7}$ Parts A and C reproduced from ref. 81 and 12 with permission from the Royal Society of Chemistry. Part B reprinted from Carbohydrate Polymers, 146, C. Wan and J. Li, Cellulose aerogels functionalized with polypyrrole and silver nanoparticles: In-situ synthesis, characterization and antibacterial activity, 362-367, Copyright 2016, with permission from Elsevier. Part D reprinted from Applied Clay Science, 101, C. S. C. Chiew P. E. Poh, P. Pasbakhsh, B. T. Tey, H. K. Yeoh, E. S. Chan, Physicochemical characterization of halloysite/alginate bionanocomposite hydrogel, 444-454, Copyright 2014, with permission from Elsevier. Part E reprinted from International Journal of Biological Macromolecules, 58, M. Liu, Y. Zhang, J. Li, C. Zhou, Chitin-natural clay nanotubes hybrid hydrogel, 23-30, Copyright 2013, with permission from Elsevier. Part F reprinted from Industrial Crops and Products, 91, L. Wang, M. Sánchez-Soto and T. Abt, Properties of bio-based gum Arabic/clay aerogels, 15-21, Copyright 2016, with permission from Elsevier. 
with sheet-like or needle-like dopants. The process might be driven by a diffusion limited aggregate (DLA) phenomenon, whereby the incorporated phase is constantly diffused and immobilized by the aggregates formed along the network of the skeletal phase. As a result, the $2 \mathrm{D}$ porous sheet structure is evolved, which resembles a coral patterns. ${ }^{3}$ In addition, the anisotropic growth of ice crystals during free drying can also create a continuous gap between the microstructures of the hybrid aerogel.

Unlike the sheet-like or needle-like dopants, these dopants have particlelike structures with a low aspect ratio that tends to produce a coating layer on the skeletal phase (Figure 7.7a and b). In some cases, the coating layer covers the entire surface of the skeletal phase forming a hollow tube structure. It is believed that the addition of metallic nanoparticles usually results in the formation of such structures.

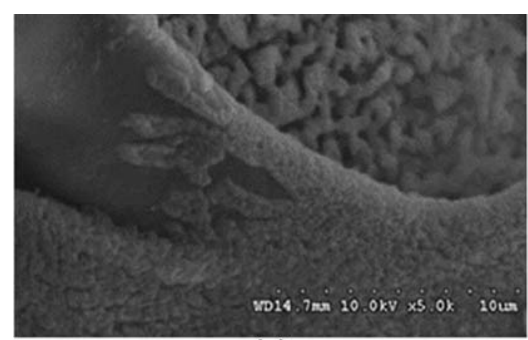

(a)

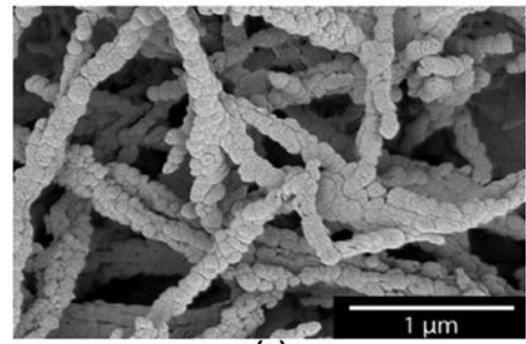

(c)

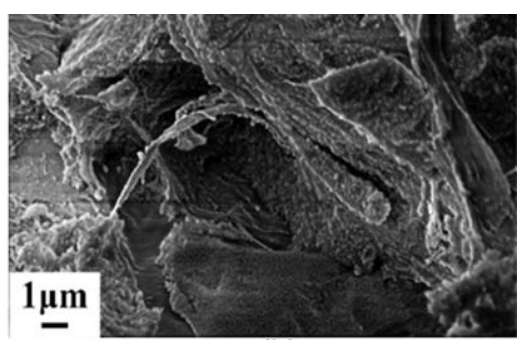

(b)

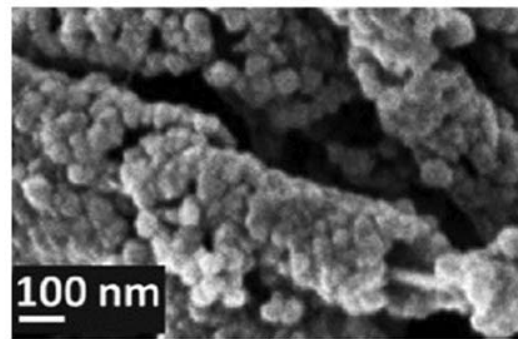

(d)

Figure 7.7 SEM images of a hybrid aerogel with an incorporated phase coated on the skeletal phase; (a) and (b) cellulose coated with silica, ${ }^{6,36}$ hollow tube structure of (c) nanocellulose fibrils coated with silica, ${ }^{72}$ and (d) bacterial cellulose templated with cobalt-ferrite nanoparticles. ${ }^{33}$ Part A reprinted from Carbohydrate Polymers, 98, J. Shi, L. Lu, W. Guo, J. Zhang and Y. Cao, Heat insulation performance, mechanics and hydrophobic modification of cellulose-SiO2 composite aerogels, 282-289, Copyright 2013, with permission from Elsevier. Part B reprinted from Carbohydrate Polymers, 147, J. Fu, S. Wang, C. He, Z. Lu, J. Huang, Z. Chen, Facilitated fabrication of high strength silica aerogels using cellulose nanofibrils as scaffold, 89-96, Copyright 2016, with permission from Elsevier. Part C reproduced from ref. 72 with permission from the Royal Society of Chemistry. Part D reproduced from Carbohydrate Polymers, 137, S. Menchaca-Nal, C. L. Londoño-Calderón, P. Cerrutti, M. L. Foresti, L. Pampillo, V. Bilovol, R. Candal and R. Martínez-García, Facile synthesis of cobalt ferrite nanotubes using bacterial nanocellulose as template, 726-731, Copyright 2016, with permission from Elsevier. 
Nanoparticles may also be anchored/grafted onto the skeletal phase without coating the entire surface (as shown in Figure 7.8). This anchoring action results from the active group reduction of the precursors of the nanoparticles as previously elucidated in Section 7.2.3(d). This makes the bio-based aerogels suitable to be used as a support or template for the synthesis, and prevents agglomeration of nanoparticles.

In addition to the method of incorporation and the aspect ratio of the dopant, the morphology of hybrid aerogels is also affected by the drying method employed. Freeze dried hybrid aerogels tend to display anisotropic microstructures (Figure 7.9) due to the anisotropic growth of ice within the pores. Liu et al. proposed a mechanism for the formation of such anisotropic structures, ${ }^{103}$ which is illustrated in Figure 7.10.

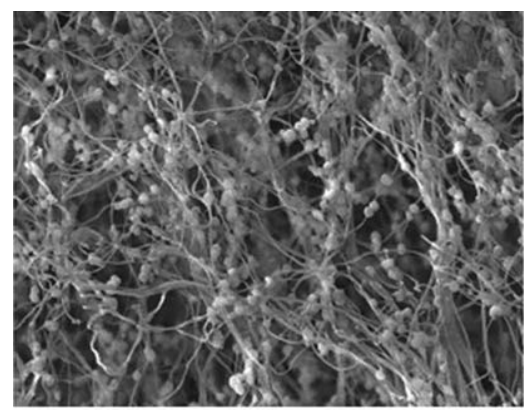

(a)

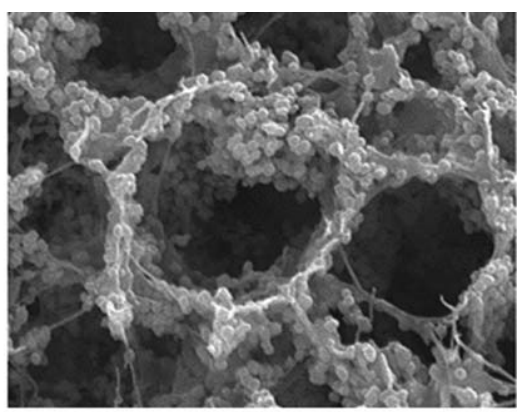

(b)

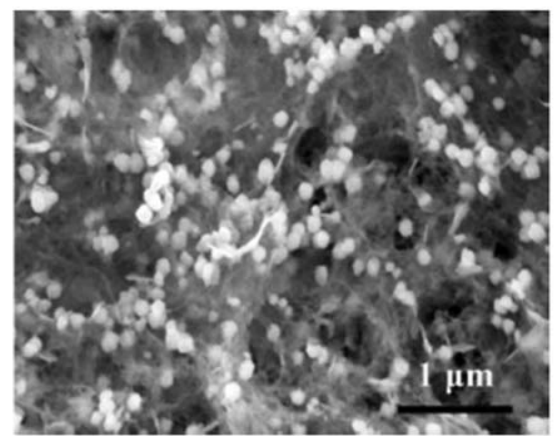

(c)

Figure 7.8 SEM images of hybrid aerogel with incorporated phase anchored/grafted onto skeletal phase; (a) and (b) bacterial nanofibril cellulose grafted with cobalt-ferrite, ${ }^{82}$ and (c) wheat straw cellulose grafted with cobalt ferrite. ${ }^{31}$ Part A and B reproduced from Nature Nanotechnology, Making flexible magnetic aerogels and stiff magnetic nanopaper using cellulose nanofibrils as templates, 5, 2010, 584-588, R. T. Olsson, M. A. S. Azizi Samir, G. Salazar-Alvarez, L. Belova, V. Ström, L. A. Berglund, O. Ikkala, J. Nogués and U. W. Gedde, Copyright 2010, with permission of Springer. Part C reprinted from Carbohydrate Polymers, 134, C. Wan and J. Li, Synthesis of well-dispersed magnetic $\mathrm{CoFe} 2 \mathrm{O} 4$ nanoparticles in cellulose aerogels via a facile oxidative co-precipitation method, 144-150, Copyright 2015, with permission from Elsevier. 
(a)

(b)

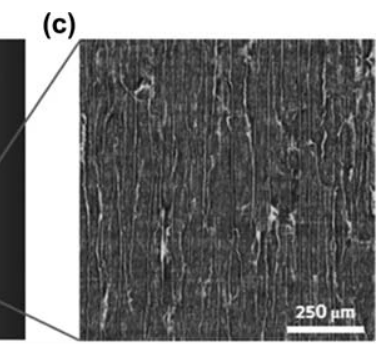

(d)
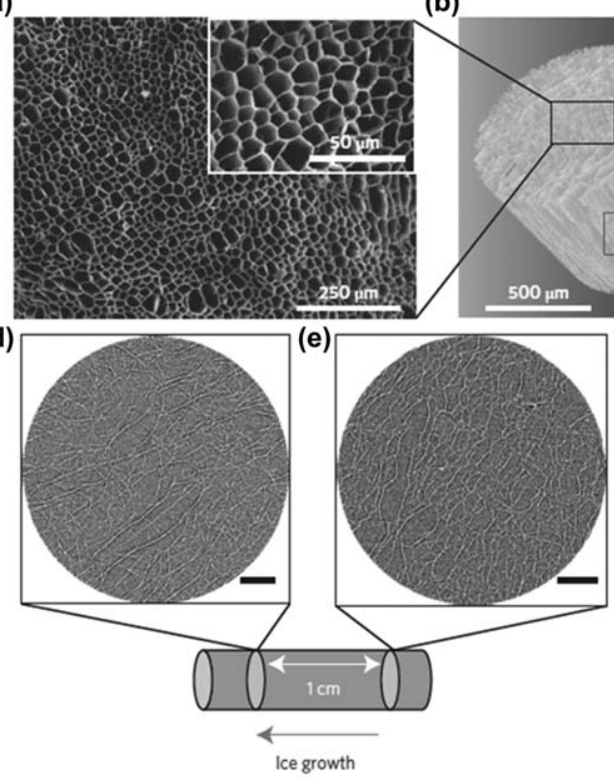

(f)

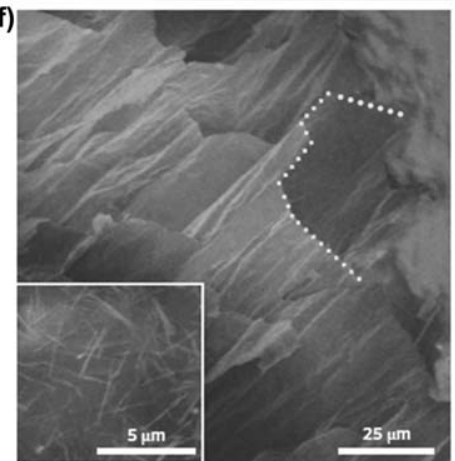

Figure 7.9 Microstructure of freeze-cast nanocomposite foams. (a) SEM crosssection image of a freeze-cast nanocomposite foam containing cellulose nanofibres (CNF), graphene oxide (GO), sepiolite (SEP) and boric acid (BA). (b) Three-dimensional reconstruction of the tubular pore structure of the nanocomposite foam derived from X-ray microtomography.

(c) X-ray microtomography image showing that the tubular pores are straight and several millimetres long in the nanocomposite foam with a composition of $77 \% \mathrm{CNF} / 10 \% \mathrm{GO} / 10 \% \mathrm{SEP} / 3 \% \mathrm{BA}$ (in wt\%). (d) and (e) X-ray microtomography cross-sections of a nanocomposite foam, taken through the upper and lower parts, respectively (scale bars, $100 \mu \mathrm{m}$ ). (f) HRSEM image of a foam wall, where the dotted line indicates a section of the tubular cell. Inset: Distributed SEP nanorods within the cell wall. The nanomaterials are homogeneously distributed in the cell walls, forming an anisotropic tubular pore structure as a result of the unidirectional freeze-casting process.

Reprinted by permission from Macmillan Publishers Limited: Nature Nanotechnology (B. Wicklein, A. Kocjan, G. Salazar-Alvarez, F. Carosio, G. Camino, M. Antonietti and L. Bergström, Nature Nanotechnology, 2015, 10, 277-283) Copyright 2015.

However, the presence of such anisotropic structures is heavily dependent on the cooling rate during freezing and the types of pore fluid it contains. This is evidenced from the cellulose-graphene oxide hybrid aerogels that were reported by two research groups using different freezing temperatures. $^{27,32}$ The results are shown in Figures 7.6(b) and 7.9(a), where both of these hybrid aerogels were freeze dried at different cooling rates. Sehaqui et al. also reported similar evidence, whereby microstructures formed near the cooling source can differ from that formed in the middle fractured section of the sample (Figure 7.11). ${ }^{62}$ The higher degree of anisotropy in the 

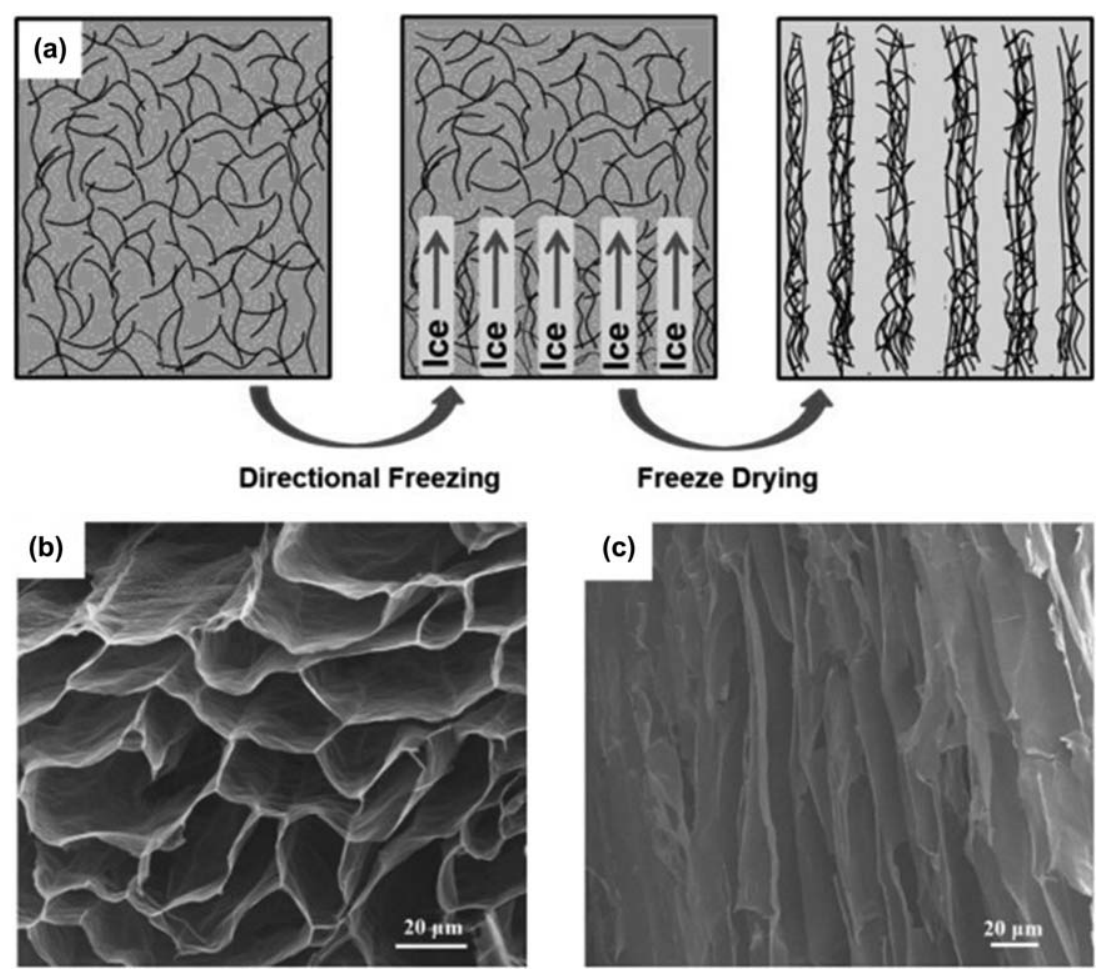

(c)

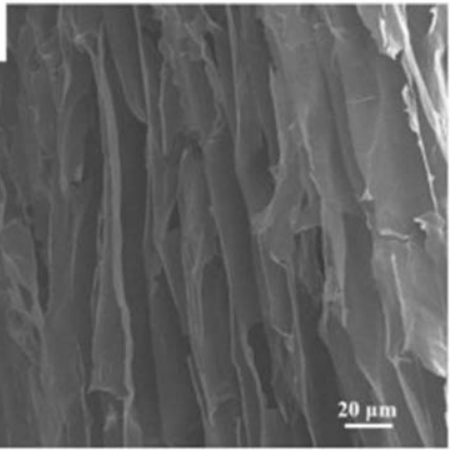

Figure 7.10 (a) A schematic illustrating the directional-freezing and freeze-drying; (b) top-view and (c) side-view SEM images of the anisotropic porous structure of AGA-8.7.

Reprinted with permission from Carbon, 100, T. Liu, M. Huang, X. Li, C. Wang, C.-X. Gui and Z.-Z. Yu, Highly compressible anisotropic graphene aerogels fabricated by directional freezing for efficient absorption of organic liquids, 456-464, Copyright 2016, with permission from Elsevier.

microstructure observed at the fractured section is caused by the anisotropic growth of ice crystals along the vertical direction. Whereas, at the surface next to the cooling source that served as the nucleation sites for ice growth, the anisotropic structure of the aerogel is less obvious. Besides the cooling rate, the nature of the pore fluid plays a critical role in creating anisotropic structures in the hybrid aerogel. Anisotropic growth of crystals from the pore fluids is favoured in the case of a polar solvent such as water, whereas when a non-polar solvent, such as liquid propane is used as a pore fluid, the 3D isotropic porous network of aerogel can be preserved. ${ }^{62}$

\subsubsection{TEM Images}

TEM plays an essential role in imaging hybrid aerogels, especially for the metal-hybrid type. TEM is used to probe the crystal structure of metallic nanoparticles doped to bio-based gels. Figures $7.12 \mathrm{c}$ and $7.13 \mathrm{~b}$ illustrate 

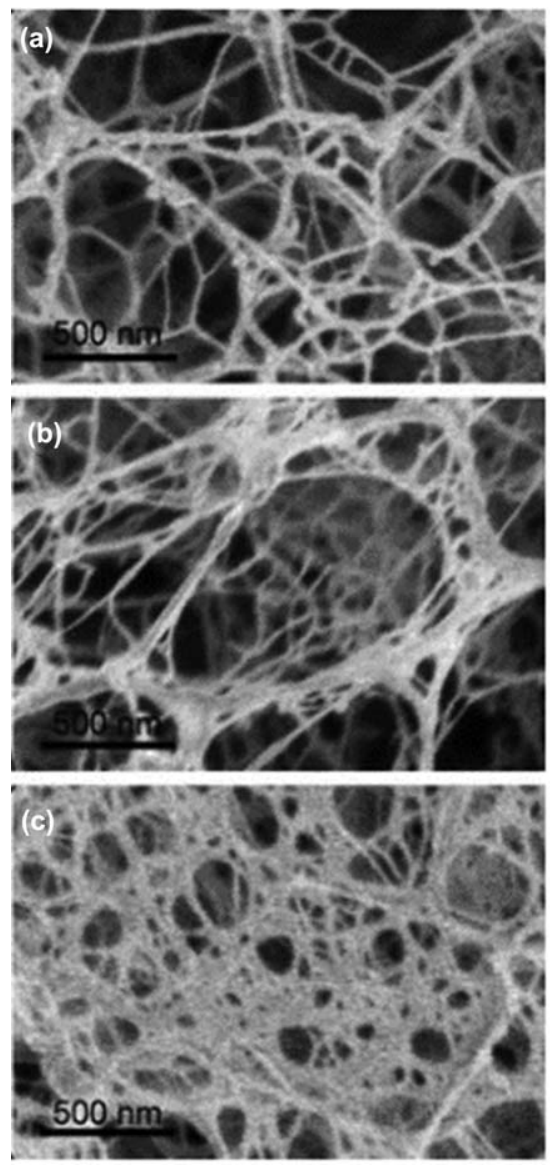
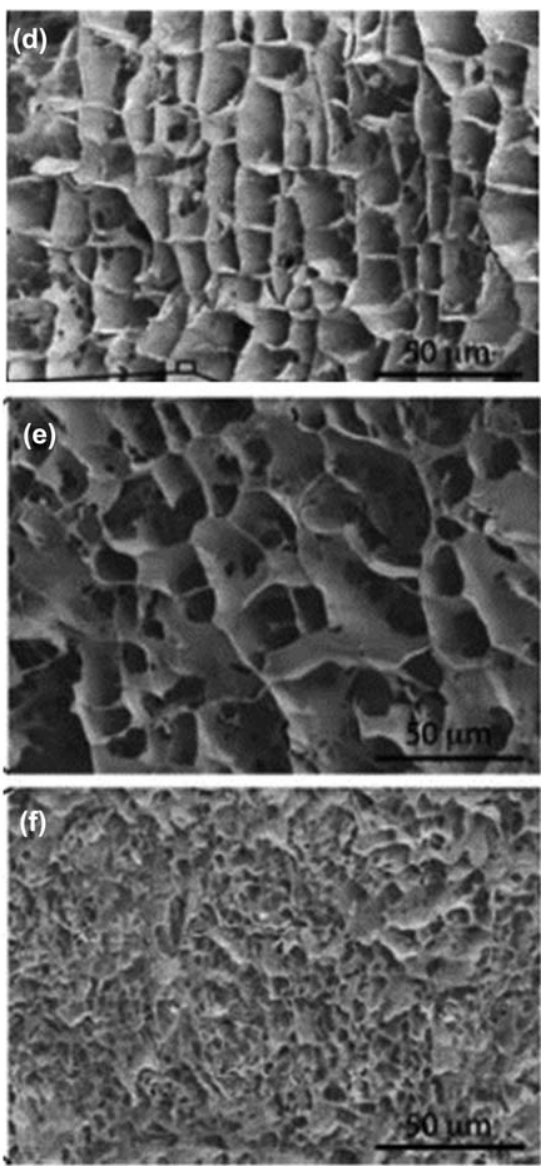

1

5

10

15

20

25 hybrid aerogels cross section at $(\mathrm{a}-\mathrm{c})$ the end of the sample next to the cooling source, $(\mathrm{d}-\mathrm{f})$ middle part of fractured sample. All pairs are compared from the lowest to highest density, which corresponds to images from top to bottom.

Reproduced from ref. 62 with permission from the Royal Society of Chemistry.

some of the crystallites in hybrid aerogels. Furthermore, TEM can give a clear picture of the distribution of nanoparticles that are anchored/grafted onto the skeletal phase. Figures 7.14 and 7.15 are examples of TEM micrographs of the cellulose skeletal phase grafted with inorganic nanoparticles.

\subsubsection{Synchrotron X-ray Tomography}

It is worth mentioning that the properties of hybrid aerogels can be greatly influenced by the degree of anisotropy in the microstructure. However, SEM and TEM images that focus on a tiny region of the composite are only able to 

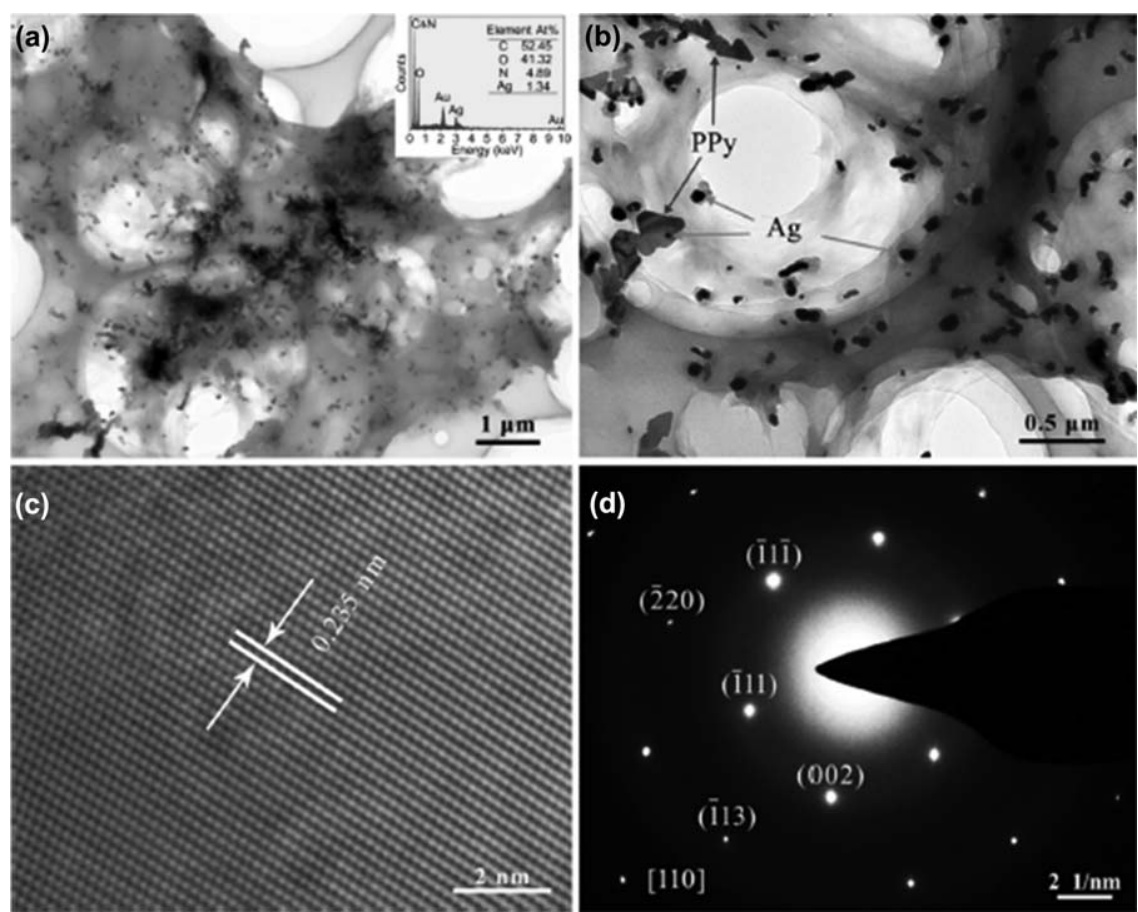

Figure 7.12 (a) Low-magnification TEM image, (b) high-magnification TEM image, (c) HRTEM image and (d) SAED pattern of Polypyrrole/silver/cellulose aerogel, respectively. C.

Adapted from Carbohydrate Polymers, 146, C. Wan and J. Li, Cellulose aerogels functionalized with polypyrrole and silver nanoparticles: In-situ synthesis, characterization and antibacterial activity, 362-367, Copyright 2016, with permission form Elsevier.
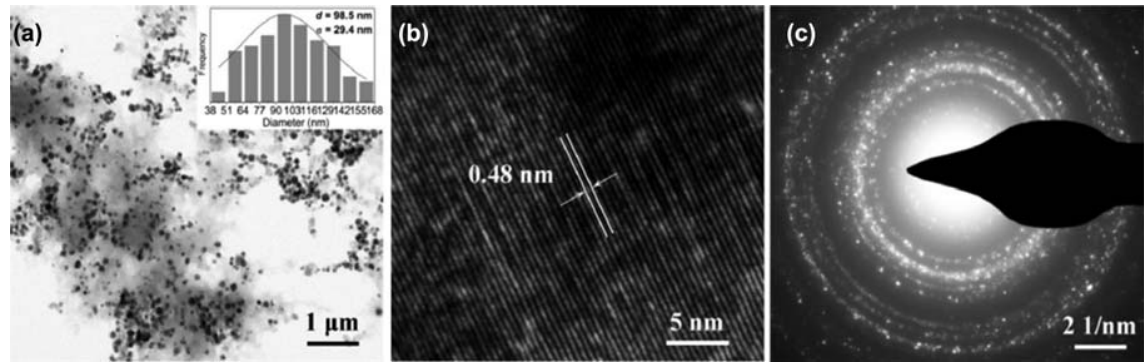

Figure 7.13 (a) TEM, (b) high-resolution TEM, and (c) SAED images of $\mathrm{CoFe}_{2} \mathrm{O}_{4}$ @ Cellulose aerogel. Inset of (a) presents the size distribution of the $\mathrm{CoFe}_{2} \mathrm{O}_{4}$ nanoparticles in a $\mathrm{CoFe}_{2} \mathrm{O}_{4} @$ Cellulose aerogel.

Reprinted from Carbohydrate Polymers, 134, C. Wan and J. Li, Synthesis of well-dispersed magnetic $\mathrm{CoFe}_{2} \mathrm{O}_{4}$ nanoparticles in cellulose aerogels via a facile oxidative co-precipitation method, 144-150, Copyright 2017, with permission from Elsevier. 

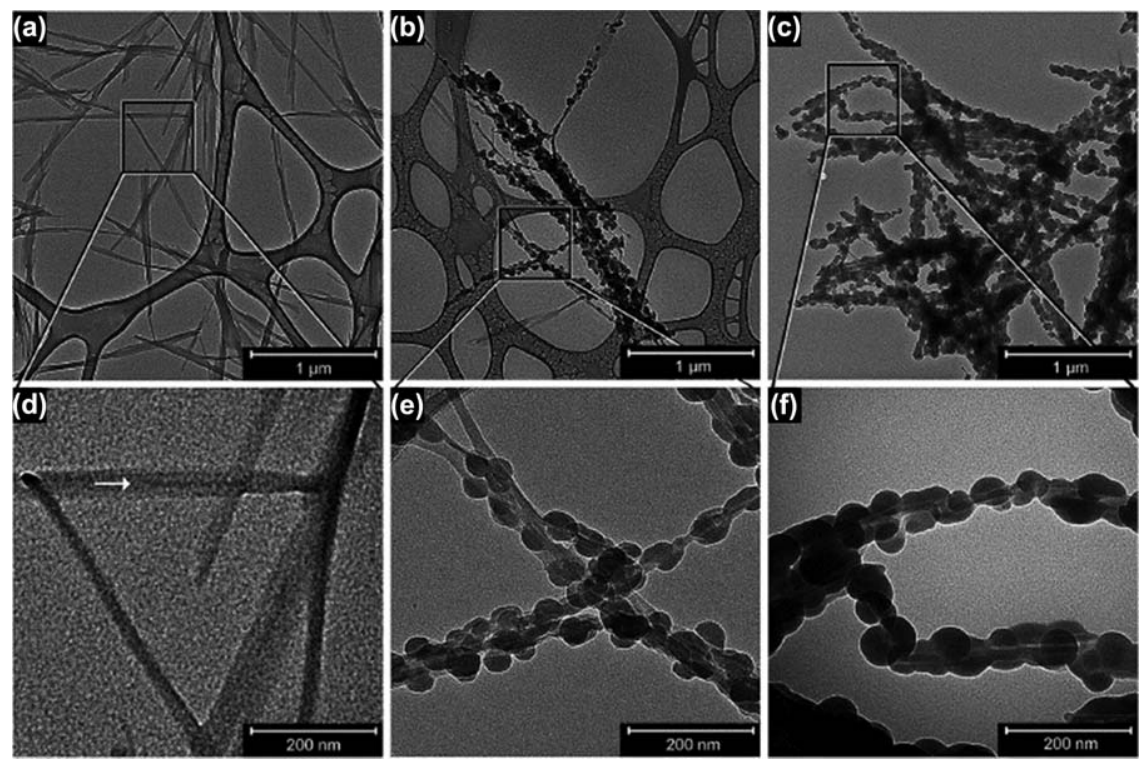

Figure 7.14 TEM images of (a) uncoated cellulose nanofibrils (CNF), (b) silica embedded with CNFs coated in 2-propanol at different CNF concentrations: $3 \mathrm{mg} \mathrm{mL}^{-1}$ and (c) $1 \mathrm{mg} \mathrm{mL}^{-1}$. (d-f) are highlighted areas from images $(\mathrm{a}-\mathrm{c})$ respectively.

Reproduced from ref. 72 with permission from the Royal Society of Chemistry.
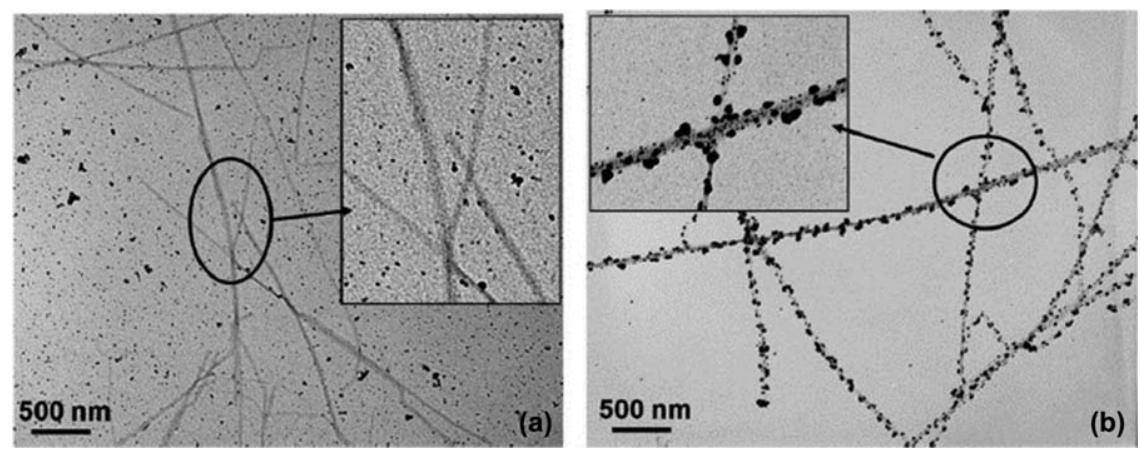

Figure 7.15 TEM images of silver nanoparticles synthesis on tunicate cellulose nanocrystals (a) without cetyltrimethylammonium bromide (CTAB) and (b) with CTAB.

Reprinted with permission from S. Padalkar, J. R. Capadona, S. J. Rowan, C. Weder, Y.-H. Won, L. A. Stanciu and R. J. Moon, Natural Biopolymers: Novel Templates for the Synthesis of Nanostructures, Langmuir, 2010, 26(11), 8497-8502, Copyright 2014 American Chemical Society. 
probe the degree of anisotropy locally, rather than giving the global picture. Amongst the research conducted in this area, Sedighi Gilani and her research group have pioneered the use of synchrotron X-ray tomography in the imaging of nano-fibrillated cellulose (NFC) incorporated into the silica aerogel. ${ }^{83}$ Figure 7.16 shows some of the tomography images reported by
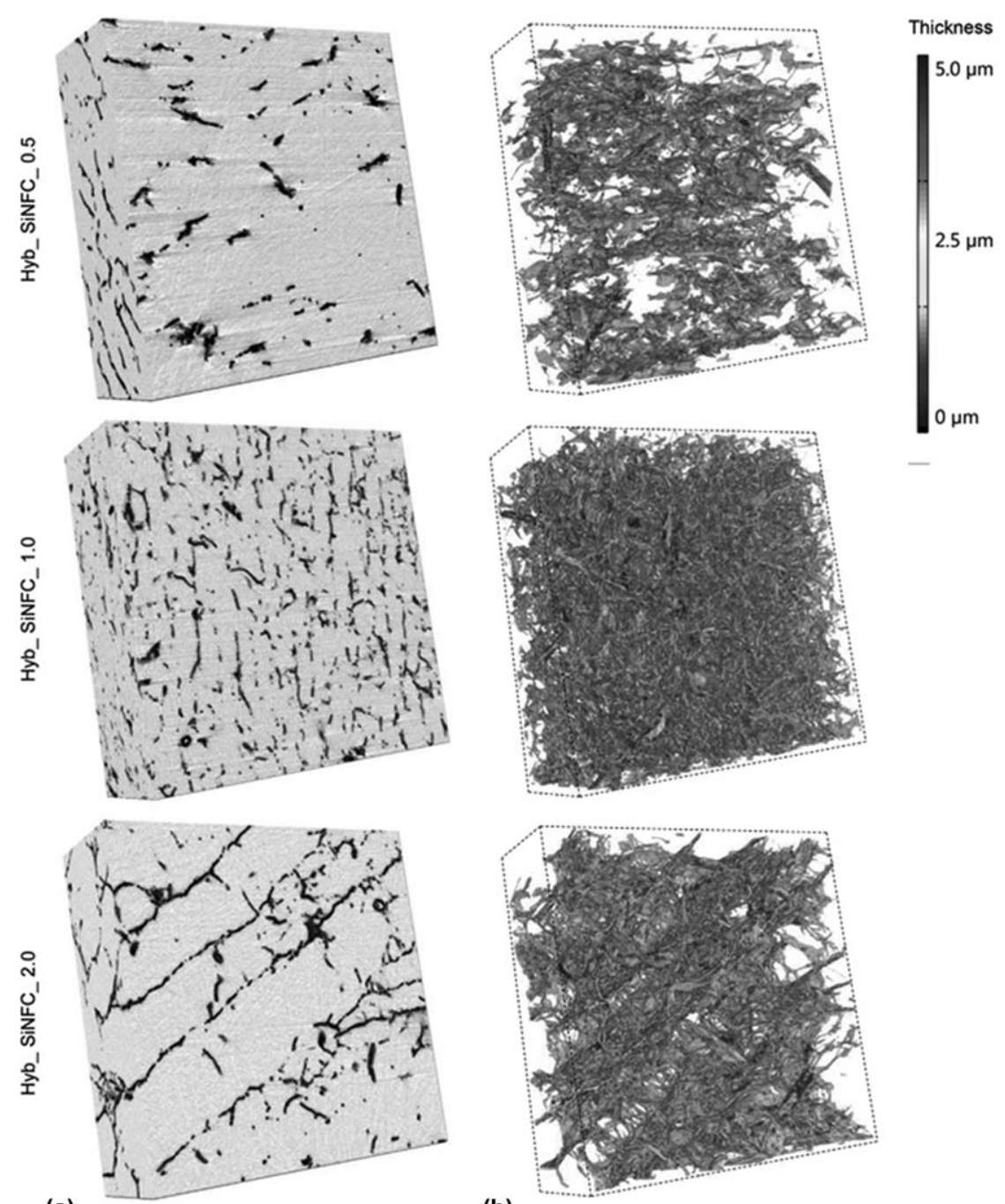

(b)

Figure 7.16 (a) 3D volume rendering of (a) silica aerogel and (b) thickness map of the respective silylated NFC scaffold.

Reprinted from Composites Science and Technology, 124, S. G. Marjan, M. N. Boone, J. L Fife, S. Zhao, M. M. Koebel, T. Zimmermann and P. Tingaut, Structure of cellulose-silica hybrid aerogel at sub-micron scale, studied by synchrotron X-ray tomographic microscopy, 71-80, Copyright 2016, with permission from Elsevier. 
this group. This technique can be very useful for hybrid aerogels, whereby the degree of anisotropy of the incorporated phase inside the skeletal phase can be visualized. This should be popularized in the study of hybrid aerogels, especially with bio-based aerogels which usually contain components with a high aspect ratio embedded in another matrix.

\subsection{Current Limitations and Future Prospects}

The commercial potential of bio-based hybrid aerogels is still limited by the same constraints faced in pure bio-based aerogels, represented by extensive solvent exchange and drying processes which are energy consuming or difficult to be scaled-up. Therefore, more research efforts should be devoted to minimizing solvent usage and to finding viable alternatives for the current drying processes. From an environmental point of view, very limited discussions have been carried out on separation and recycling $\mathrm{CO}_{2}$ in the supercritical $\mathrm{CO}_{2}$ drying processes. Furthermore, there is very scarce research on how to manipulate the orientation of the incorporated phase into the matrix. The ability to do so would that indicate real-time tunable properties of the hybrid aerogel have formed. Such achievements would definitely revolutionize the use of hybrid aerogels, which in return would benefit many applications, especially in tissue engineering and pharmaceuticals.

\section{References}

1. H.-B. Chen, Y.-Z. Wang and D. A. Schiraldi, Eur. Polym. J., 2013, 49, 3387-3391.

2. D. J. Boday, B. Muriithi, R. J. Stover and D. A. Loy, J. Non-Crystal. Solids, 2012, 358, 1575-1580.

3. G. Hayase, K. Kanamori, K. Abe, H. Yano, A. Maeno, H. Kaji and K. Nakanishi, ACS Appl. Mater. Interfaces, 2014, 6, 9466-9471.

4. A. Javadi, Q. Zheng, F. Payen, A. Javadi, Y. Altin, Z. Cai, R. Sabo and S. Gong, ACS Appl. Mater. Interfaces, 2013, 5, 5969-5975.

5. B. Seantier, D. Bendahou, A. Bendahou, Y. Grohens and H. Kaddami, Carbohydr. Polym., 2016, 138, 335-348.

6. J. Shi, L. Lu, W. Guo, J. Zhang and Y. Cao, Carbohydr. Polym., 2013, 98, 282-289.

7. L. Wang, M. Sánchez-Soto and T. Abt, Ind. Crops Prod., 2016, 91, 15-21.

8. S. Zhao, W. J. Malfait, E. Jeong, B. Fischer, Y. Zhang, H. Xu, E. Angelica, W. M. Risen, J. W. Suggs and M. M. Koebel, ACS Sustainable Chem. Eng., 2016, 4, 5674-5683.

9. S. Zhao, Z. Zhang, G. Sèbe, R. Wu, R. V. Rivera Virtudazo, P. Tingaut and M. M. Koebel, Adv. Funct. Mater., 2015, 25, 2326-2334.

10. X. Liu and W. M. Risen, in Natural Fibers, Plastics and Composites, ed. T. W. Frederick and E. W. Norman, Kluwer, Boston, 2004.

11. A. El Kadib and M. Bousmina, Chemistry, 2012, 18, 8264-8277. 
12. A. A. Alhwaige, T. Agag, H. Ishida and S. Qutubuddin, RSC Adv., 2013, 3, 16011-16020.

13. S. Antonyuk, S. Heinrich, P. Gurikov, S. Raman and I. Smirnova, Powder Technol., 2015, 285, 34-43.

14. H. Ennajih, R. Bouhfid, E. M. Essassi, M. Bousmina and A. El Kadib, Microporous Mesoporous Mater., 2012, 152, 208-213.

15. M. S. Sajab, C. H. Chia, C. H. Chan, S. Zakaria, H. Kaco, S. W. Chook, S. X. Chin and A. A. M. Noor, RSC Adv., 2016, 6, 19819-19825.

16. A. Djelad, A. Morsli, M. Robitzer, A. Bengueddach, F. di Renzo and F. Quignard, Molecules, 2016, 21, E109.

17. R.-L. Liu, X.-Q. Li, H.-Q. Liu, Z.-M. Luo, J. Ma, Z.-Q. Zhang and Q. Fu, RSC Adv., 2016, 6, 30301-30310.

18. Y. Wang, S. Yadav, T. Heinlein, V. Konjik, H. Breitzke, G. Buntkowsky, J. J. Schneider and K. Zhang, RSC Adv., 2014, 4, 21553-21558.

19. X. Yang, Thesis, McMaster University, 2014.

20. T. Zhai, Q. Zheng, Z. Cai, H. Xia and S. Gong, Carbohydr. Polym., 2016, 148, 300-308.

21. Q. Zheng, Z. Cai and S. Gong, J. Mater. Chem. A, 2014, 2, 3110-3118.

22. A. Demilecamps, Thesis, Ecole Nationale Supérieure des Mines de Paris, 2015.

23. J. Feng, D. Le, S. T. Nguyen, V. Tan Chin Nien, D. Jewell and H. M. Duong, Colloids Surf., A, 2016, 506, 298-305.

24. Y. Han, X. Zhang, X. Wu and C. Lu, ACS Sustainable Chem. Eng., 2015, 3, 1853-1859.

25. N. Leventis, A. Sadekar, N. Chandrasekaran and C. Sotiriou-Leventis, Chem. Mater., 2010, 22, 2790-2803.

26. L. Wang, D. A. Schiraldi and M. Sánchez-Soto, Ind. Eng. Chem. Res., 2014, 53, 7680-7687.

27. B. Wicklein, A. Kocjan, G. Salazar-Alvarez, F. Carosio, G. Camino, M. Antonietti and L. Bergström, Nat. Nanotechnol., 2015, 10, 277-283.

28. B. Yuan, J. Zhang, J. Yu, R. Song, Q. Mi, J. He and J. Zhang, Sci. China: Chem., 2016, 59, 1335-1341.

29. S. Zhao, W. J. Malfait, A. Demilecamps, Y. Zhang, S. Brunner, L. Huber, P. Tingaut, A. Rigacci, T. Budtova and M. M. Koebel, Angew. Chem., Int. Ed., 2015, 54, 14282-14286.

30. P. Hao, Z. Zhao, Y. Leng, J. Tian, Y. Sang, R. I. Boughton, C. P. Wong, H. Liu and B. Yang, Nano Energy, 2015, 15, 9-23.

31. C. Wan and J. Li, Carbohydr. Polym., 2015, 134, 144-150.

32. C. Wan and J. Li, Carbohydr. Polym., 2016, 150, 172-179.

33. S. Menchaca-Nal, C. L. Londoño-Calderón, P. Cerrutti, M. L. Foresti, L. Pampillo, V. Bilovol, R. Candal and R. Martínez-García, Carbohydr. Polym., 2016, 137, 726-731.

34. S. Liu, Q. Yan, D. Tao, T. Yu and X. Liu, Carbohydr. Polym., 2012, 89, 551557.

35. L. Baldino, S. Cardea and E. Reverchon, Chem. Eng. Trans., 2015, 43, 739-744. 
36. J. Fu, S. Wang, C. He, Z. Lu, J. Huang and Z. Chen, Carbohydr. Polym., 2016, 147, 89-96.

37. M. Liu, L. Dai, H. Shi, S. Xiong and C. Zhou, Mater. Sci. Eng., C, 2015, 49, 700-712.

38. S. Quraishi, M. Martins, A. A. Barros, P. Gurikov, S. P. Raman, I. Smirnova, A. R. C. Duarte and R. L. Reis, J. Supercrit. Fluids, 2015, 105, 1-8.

39. M. Betz, C. A. García-González, R. P. Subrahmanyam, I. Smirnova and U. Kulozik, J. Supercrit. Fluids, 2012, 72, 111-119.

40. M. A. Marin, R. R. Mallepally and M. A. McHugh, J. Supercrit. Fluids, 2014, 91, 84-89.

41. M. R. Ayers and A. J. Hunt, J. Non-Cryst. Solids, 2001, 285, 123-127.

42. V. S. S. Gonçalves, P. Gurikov, J. Poejo, A. A. Matias, S. Heinrich, C. M. M. Duarte and I. Smirnova, Eur. J. Pharm. Biopharm., 2016, 107, 160-170.

43. J. Rooke, C. de Matos Passos, M. Chatenet, R. Sescousse, T. Budtova, S. Berthon-Fabry, R. Mosdale and F. Maillard, J. Electrochem. Soc., 2011, 158, B779-B789.

44. H. Wang, Z. Shao, M. Bacher, F. Liebner and T. Rosenau, Cellulose, 2013, 20, 3007-3024.

45. J. Cai, S. Kimura, M. Wada and S. Kuga, Biomacromolecules, 2009, 10, 87-94.

46. C. Wan and J. Li, Mater. Des., 2015, 83, 620-625.

47. D. Dutta, R. Hazarika, P. D. Dutta, T. Goswami, P. Sengupta and D. K. Dutta, RSC Adv., 2016, 6, 85173-85181.

48. S. Zhao, H. Xu, L. Wang, P. Zhu, W. M. Risen Jr and J. William Suggs, Microporous Mesoporous Mater., 2013, 171, 147-155.

49. C. Wan and J. Li, Carbohydr. Polym., 2016, 146, 362-367.

50. C. Yao, X. Liu and M. R. William, in Aerogels Handbook, ed. M. A. Aegerter, N. Leventis and M. M. Koebel, Springer, New York, 2011.

51. X. Hu, S. Ji and W. M. Risen, MRS Proc., 2001, 702.

52. X. Liu, Y. Zhu, C. Yao and W. M. Risen, MRS Proc., 2003, 788.

53. C. Yao and M. R. J. William, MRS Proc., 2005, 847, 515-520.

54. C. Yao, X. Liu and W. M. Risen, MRS Proc., 2005, 888.

55. N. Kuthirummal, A. Dean, C. Yao and W. Risen Jr, Spectrochim. Acta, Part A, 2008, 70, 700-703.

56. X. Liu, 2005,

57. X. Liu, C. Yao and W. M. Risen, MRS Proc., 2005, 899.

58. Z. Liu, P. Wu, S. Yang, H. Wang and C. Jin, Int. J. Polym. Sci., 2016, 2016, 8.

59. X. Hu, K. Littrel, S. Ji, D. G. Pickles and W. M. Risen Jr, J. Non-Cryst. Solids, 2001, 288, 184-190.

60. I. Josef, K. W. Hedda and K. Gregor, Lenzinger Ber., 2006, 86, 137-143.

61. M. Ahmadi, A. Madadlou and A. A. Saboury, Food Chem., 2016, 196, 1016-1022. 
62. H. Sehaqui, M. Salajkova, Q. Zhou and L. A. Berglund, Soft Matter, 2010, 6, 1824-1832.

63. C. Wan, Y. Lu, Y. Jiao, C. Jin, Q. Sun and J. Li, J. Appl. Polym. Sci., 2015, 132, 42037-42044.

64. T. Lu, Q. Li, W. Chen and H. Yu, Compos. Sci. Technol., 2014, 94, 132-138.

65. X. Zhang, Y. Wang, J. Zhao, M. Xiao, W. Zhang and C. Lu, ACS Sustain. Chem. Eng., 2016, 4, 4321-4327.

66. N. Pircher, S. Veigel, N. Aigner, J. M. Nedelec, T. Rosenau and F. Liebner, Carbohydr. Polym., 2014, 111, 505-513.

67. A. A. Alhwaige, Case Western Reserve University, 2014.

68. S. P. Raman, P. Gurikov and I. Smirnova, J. Supercrit. Fluids, 2015, 106, 23-33.

69. A. S. Ahmad, K. A. Dzulkefly and D. Rusli, Cellulose Chem. Technol., 2012, 46, 45-52.

70. H.-B. Zhao, L. Yuan, Z.-B. Fu, C.-Y. Wang, X. Yang, J.-Y. Zhu, J. Qu, H.-B. Chen and D. A. Schiraldi, ACS Appl. Mater. Interfaces, 2016, 8, 9917-9924.

71. H. Dong, J. F. Snyder, D. T. Tran and J. L. Leadore, Carbohydr. Polym., 2013, 95, 760-767.

72. D. Liu, Q. Wu, R. L. Andersson, M. S. Hedenqvist, S. Farris and R. T. Olsson, J. Mater. Chem. A, 2015, 3, 15745-15754.

73. J. Cai, S. Liu, J. Feng, S. Kimura, M. Wada, S. Kuga and L. Zhang, Angew. Chem. Int. Ed., 2012, 51, 2076-2079.

74. D. Bendahou, A. Bendahou, B. Seantier, Y. Grohens and H. Kaddami, Ind. Crops Prod., 2015, 65, 374-382.

75. S. Zhou, M. Wang, X. Chen and F. Xu, ACS Sustain. Chem. Eng., 2015, 3, 3346-3354.

76. M. Kettunen, R. J. Silvennoinen, N. Houbenov, A. Nykänen, J. Ruokolainen, J. Sainio, V. Pore, M. Kemell, M. Ankerfors and T. Lindström, Adv. Funct. Mater., 2011, 21, 510-517.

77. J. T. Korhonen, M. Kettunen, R. H. A. Ras and O. Ikkala, ACS Appl. Mater. Interfaces, 2011, 3, 1813-1816.

78. C. Schütz, J. Sort, Z. Bacsik, V. Oliynyk, E. Pellicer, A. Fall, L. Wågberg, L. Berglund, L. Bergström and G. Salazar-Alvarez, PLoS One, 2012, 7, e45828.

79. M. Wang, I. V. Anoshkin, A. G. Nasibulin, J. T. Korhonen, J. Seitsonen, J. Pere, E. I. Kauppinen, R. H. A. Ras and O. Ikkala, Adv. Mater., 2013, 25, 2428-2432.

80. L. Melone, L. Altomare, I. Alfieri, A. Lorenzi, L. De Nardo and C. Punta, J. Photochem. Photobiol. A: Chem., 2013, 261, 53-60.

81. M. Wang, I. V. Anoshkin, A. G. Nasibulin, R. H. A. Ras, Nonappa, J. Laine, E. I. Kauppinen and O. Ikkala, RSC Adv., 2016, 6, 89051-89056.

82. R. T. Olsson, M. A. S. Azizi Samir, G. Salazar Alvarez, L. Belova, V. Strom, L. A. Berglund, O. Ikkala, J. Nogues and U. W. Gedde, Nat. Nano, 2010, 5, 584-588. 
83. M. Sedighi Gilani, M. N. Boone, J. L. Fife, S. Zhao, M. M. Koebel, T. Zimmermann and P. Tingaut, Compos. Sci. Technol., 2016, 124, 71-80.

84. Q. Ma, Y. Liu, Z. Dong, J. Wang and X. Hou, J. Appl. Polym. Sci., 2015, 132, 41770-41781.

85. J. Wang, Q. Zhou, D. Song, B. Qi, Y. Zhang, Y. Shao and Z. Shao, J. Sol-Gel Sci. Technol., 2015, 76, 501-509.

86. C. J. Yao, X. Liu and W. M. Risen, in Aerogels Handbook, ed. M. A. Aegerter, N. Leventis and M. M. Koebel, Springer New York, New York, 2011, pp. 385-401.

87. M. Liu, Y. Zhang, J. Li and C. Zhou, Int. J. Biol. Macromol., 2013, 58, 23-30.

88. Z. Ulker and C. Erkey, RSC Adv., 2014, 4, $62362-62366$.

89. S. Zhao, G. Zhang, Y. Gao, L. Deng, J. Li, R. Sun and C.-P. Wong, ACS Appl. Mater. Interfaces, 2014, 6, 22823-22829.

90. X. Shen, J. L. Shamshina, P. Berton, G. Gurau and R. D. Rogers, Green Chem., 2016, 18, 53-75.

91. H. Wei, K. Rodriguez, S. Renneckar and P. J. Vikesland, Environ. Sci.: Nano, 2014, 1, 302-316.

92. M. Deng, Q. Zhou, A. Du, J. van Kasteren and Y. Wang, Mater. Lett., 2009, 63, 1851-1854.

93. P. Gurikov, S. P. Raman, D. Weinrich, M. Fricke and I. Smirnova, RSC Adv., 2015, 5, 7812-7818.

94. J. Zhang, Y. Cao, J. Feng and P. Wu, J. Phys. Chem. C, 2012, 116, 8063-8068.

95. R. J. B. Pinto, M. C. Neves, C. P. Neto and T. Trindade, Compos. Cellulose Met. Nanopart., 2012.

96. M. Ahmadi, A. Madadlou and A. A. Sabouri, Food Chem., 2015, 174, 97-103.

97. Q. Peng, M. Liu, J. Zheng and C. Zhou, Microporous Mesoporous Mater., 2015, 201, 190-201.

98. H.-B. Chen, B.-S. Chiou, Y.-Z. Wang and D. A. Schiraldi, ACS Appl. Mater. Interfaces, 2013, 5, 1715-1721.

99. M. M. Koebel, L. Huber, S. Zhao and W. J. Malfait, J. Sol-Gel Sci. Technol., 2016, 79, 308-318.

100. B. Lucia, C. Simona, C. Stefano, M. Iolanda De and R. Ernesto, J. Supercrit. Fluids, 2015, 103, 70-76.

101. H. Lindy, Z. Lifan and T. Wim, ChemSusChem, 2013, 1-9.

102. C. S. C. Chiew, P. E. Poh, P. Pasbakhsh, B. T. Tey, H. K. Yeoh and E. S. Chan, Appl. Clay Sci., 2014, 101, 444-454.

103. T. Liu, M. Huang, X. Li, C. Wang, C.-X. Gui and Z.-Z. Yu, Carbon, 2016, 100, 456-464. 